\title{
Thyroid Gland Medullary Carcinoma by AJCC v8 Stage
}

National Cancer Institute

\section{Source}

National Cancer Institute. Thyroid Gland Medullary Carcinoma by A/CC v8 Stage. NCI

Thesaurus. Code C141042.

A term that refers to the staging of thyroid gland medullary carcinoma, following the rules of the TNM AJCC V8 classification system. Differentiated and anaplastic thyroid gland carcinomas are staged according to the classification for thyroid-differentiated and anaplastic carcinoma. (from AJCC 8th Ed.) 